\title{
Clinical Management of a Patient with Drug Dependence Who Attempted Suicide While Receiving Peginterferon Therapy for Chronic Hepatitis C
}

\begin{abstract}
Bruno Cópio Fábregas ${ }^{1,2}$, Alexandre Sampaio Moura ${ }^{2}$, Renata Cristiane Marciano ${ }^{1}$, Ricardo Andrade Carmo² and Antônio Lúcio Teixeira ${ }^{1,3}$ ${ }^{1}$ Neuropsychiatry Group, Neurology Division, University Hospital, Federal University of Minas Gerais; ${ }^{2}$ Infectious Diseases Reference CenterCTR-DIP Orestes Diniz, Municipal Health Division/ Federal University of Minas Gerais; ${ }^{3}$ Department of Internal Medicine, School of Medicine, Federal University of Minas Gerais; Belo Horizonte, MG, Brazil
\end{abstract}

\begin{abstract}
Pegylated interferon-alpha combined with ribavirin is the current gold standard treatment for chronic hepatitis C. Illicit drug dependence is not a rare co-morbidity among chronic hepatitis $\mathbf{C}$ population, what can make antiviral treatment an outmost challenge. Despite high sustained virological response rate following antiviral treatment, serious psychiatric adverse reactions may occur, like depression and suicide attempt. We report a patient with recurrent depressive disorder, previous history of suicide attempt and illicit drug dependence. We discuss the singularities and challenges of managing this patient in order to complete the antiviral treatment.

Key-Words: Interferon-alpha, chronic hepatitis C, depression, suicide attempt, drug addiction.
\end{abstract}

Chronic hepatitis C (CHC) is a major worldwide health problem with an estimated 170 millions of people infected with the hepatitis C virus (HCV) around the world [1]. Approximately $20 \%$ of chronic HCV carriers eventually develop cirrhosis and 1-4\% are diagnosed with hepatocelular carcinoma per year [2]. Due to these liver complications, CHC is among the most common causes of liver transplantation [3]. The antiviral treatment of CHC with a combination of pegylated interferon- $\alpha$ (IFN- $\alpha$ ) and ribavirin (RBV) is the current standard care resulting in sustained virological response in $45 \%$ to $80 \%$ of patients [4-5].

It is recognized that psychiatric patients have higher rates of sexually and bloodborne transmitted infections, including CHC. A recent review study [6] showed wide variability of $\mathrm{CHC}$ prevalence rates in the psychiatric population. Some researchers in the United States have found $\mathrm{CHC}$ exposure rates as high as $38 \%$, and others as low as $8.2 \%$. The lowest $\mathrm{CHC}$ rates in psychiatric patients were found in developing countries, 2.6\% [7] and 5.7\% [8] in Brazil, and 6.8\% in Taiwan [9]. It is worth reminding that the estimated prevalence of $\mathrm{CHC}$ in the general population of the Brazilian municipality of São Paulo [10] is $1.4 \%$. Drug dependence should also be considered as a possible factor associated to increased risk for CHC [7].

Furthermore, depressive symptoms secondary to IFN- $\alpha$ treatment occurs in approximately $10 \%-40 \%$ of patients [11] and they are a major cause of drug interruption with a negative impact in treatment response rates. Suicidal ideation and attempt are considered reasons for prompt treatment interruption. However it might be possible to complete treatment in selected patients with careful multidisciplinary approach. Herein we describe a case on which we managed to Received on 17 May 2009; revised 18 July 2009.

Address for correspondence: Dr. Bruno Cópio Fábregas. Rua Padre Rolim 815/202, Belo Horizonte, Minas Gerais. Zip code: 30130-090. Fax: 55-31-3409-2651. E-mail: brunofabregas@yahoo.com.br.

The Brazilian Journal of Infectious Diseases 2009;13(5):387-390. (C) 2009 by The Brazilian Journal of Infectious Diseases and Contexto Publishing. All rights reserved. finish a 48-week combined treatment in an HCV-infected patient with depression and drug dependence that attempted suicide on week 11.

\section{Case Report}

In October 2006, a 46-year-old man was referred for treatment evaluation at a public university-based service of infectious diseases (CTR-DIP Orestes Diniz-SMSA-BH/ UFMG) in Belo Horizonte, Minas Gerais, Brazil. He was diagnosed with HCV infection two years earlier, but was asymptomatic and denied any previous symptoms related to either acute or chronic hepatitis.

The patient had a previous history of illicit drug use, including intravenous cocaine and inhaled crack since 18 years old. He alleged that he had quit illicit drug use four months earlier. He reported alcohol intake until a month earlier and had a history of 35 pack-years of smoking. The patient reported an irregular psychiatric treatment for recurrent depressive disorder. He had been admitted to psychiatric ward three times and all were related to illicit drug abuse. He also had one suicide attempt associated with an episode of drug overdose 15 years before.

He had type- 2 diabetes, hypertension and a history of ischemic heart disease. His prescription included metformin (750 mg/d), captopril (25 mg tid), acetylsalicylic acid (100 mg/ d), amitriptyline ( $75 \mathrm{mg} / \mathrm{d}$ ) and clonazepam ( $2 \mathrm{mg} / \mathrm{d}$ ).

On physical examination, the patient appeared healthy without jaundice or other signs of hepatic dysfunction. His vital signs were normal and he did not have liver or spleen enlargement.

The results of a complete blood examination were all within the normal range except for his fasting glucose $(130 \mathrm{mg} / \mathrm{dL})$, glycated haemoglobin $(7.1 \mathrm{~g} / \mathrm{dL})$, alanine aminotransferase (89 U/L) and aspartate aminotransferase (68 U/L). He had a positive HCV-RNA qualitative PCR test, a genotype test showing HCV 1a, and an HCV quantitative PCR test showing a low HCV viral load (45.700 UI/mL). His liver percutaneous biopsy showed an intense inflammatory infiltrate with interface and lobular necrosis along with bridging fibrosis (Metavir A3 F3). He tested negative for HIV and HBsAg. 
Due to his advanced fibrosis and elevated liver enzymes, combined 48-week antiviral treatment with pegylated interferon- $\alpha$ 2b (1.5 mcg/kg) plus ribavirin (1250 mg/d) was started. His previous psychiatric history with illicit drug use and suicide attempt warranted a careful psychiatric evaluation and follow up. Thus, the patient was referred to a psychiatrist.

The patient was seen bi-weekly by the infectious disease specialist. He was always followed by his wife who gave him full support. On week 4 of HCV treatment, the patient was very anxious with memory complaints and had increased by himself amitriptyline dose to $125 \mathrm{mg} / \mathrm{d}$. He had an appointment with the psychiatrist who kept clonazepam at the same dose but withdraw amitriptyline. This decision was based on the elevated anticholinergic effect of amitriptyline that could impact negatively in cognition, notably in memory function. Citalopram (20 mg/d) was started to control depressive and anxious symptoms.

The patient missed his appointment at treatment week 10 and showed up two weeks later. He reported one episode of intravenous cocaine use. Following drug consumption he attempted suicide by trying to cut his wrists. Due to this episode, he had been admitted to a psychiatric hospital where levomepromazine (75 mg/d) and clomipramine (75 mg/d) were added to his prescription. After 5 days of hospital stay, he returned to our clinic complaining a series of depressive symptoms, such as insomnia, loss of appetite, lack of interest, low self esteem, ideas of guilt, and anxiety. We decided to switch citalopram for bupropion and the immediate suspension of IFN- $\alpha$ was considered. The risks of continuing IFN- $\alpha$ treatment were openly discussed with the patient and his wife. Nevertheless, as the patient expressed firmly desire to finish treatment, IFN- $\alpha$ was maintained. The patient started to have appointments in a weekly basis. He could also contact the medical staff by phone at any time as required.

On follow-up, using bupropion (150 mig BID), clomipramine (75 mg/d), levomepromazine (75 mg/d) and clonazepam (2 mg/ d), he evolved with improvement of drug craving and complete remission of depressive symptoms, as well as fatigue and cognitive complaints. He did not relapsed illicit drug use until HCV treatment completion. He presented a negative qualitative HCV PCR test both at the end of treatment and 24 weeks after treatment completion.

However four months after the end of treatment he started again illicit drug use (crack), developing aggressive behavior and frequent involvement in street fights. Unfortunately, seven months after HCV treatment completion, his wife showed up at the infectious diseases referral center informing that he was beaten at the street and suffered serious head and abdominal injuries, dying from related complications.

\section{Discussion}

In CHC treatment centers, it is common for health professionals to deal with patients presenting substance abuse or dependence and psychiatric disorders associated or not with IFN- $\alpha$ treatment [12-14]. One study in the United
States [15] with severe mental illness patients found significant association between drug use and elevated risk for $\mathrm{CHC}$, especially crack use and intravenous cocaine use. The patient of our study presented both risk factors according to his previous clinical history.

Besides that, patients receiving IFN- $\alpha$ develop a myriad of depressive-related symptoms that, while clinically meaningful, do not meet full Diagnostic and Statistical Manual of Mental Disorders (DSM-IV) criteria for major depression [16]. Thus, rates of depression seem to be higher when this condition is searched by means of symptom inventories rather than according to DSM-IV criteria. The incidence of major depression in patients with $\mathrm{CHC}$ that receive IFN- $\alpha$ varies significantly, with most reports describing frequencies between $10 \%$ to $40 \%[11,17,18]$. This wide variation may be explained by different methodological issues and characteristics of the CHC samples studied. Our patient had the DSM-IV criteria for the diagnosis of major depression during antiviral treatment. It is uncertain whether this syndrome was secondary to IFN- $\alpha$ treatment, represented an episode of the patient's recurrent disease or both conditions. Several theories try to explain the pathophysiology of depression induced by IFN- $\alpha$, most of them include monoamine alterations, specially serotonin. For instance, patients who received pegylated IFN- $\alpha 2 \mathrm{~b}$ and developed depression during treatment presented lower levels of the serotonin metabolite 5-hydroxyindoleacetic acid (5-HIAA) in the cerebrospinal fluid [19]. The involvement of serotonin pathway is also corroborated by the fact that selective serotonin reuptake inhibitors are effective in the treatment of IFN- $\alpha$-induced depression [20]. Furthermore, IFN- $\alpha$ administration significantly increases plasma ACTH, cortisol and pro-inflammatory cytokines concentrations in patients who develop depression [21].

The relevance of an appropriate treatment for depression in $\mathrm{CHC}$ patients during IFN- $\alpha / \mathrm{RBV}$ therapy was shown by Raison et al. [17]. This study evaluated 102 patients by the Zung's Self-rating Depression Scale (SDS). Only 34\% of subjects who presented 20 point or greater increase in SDS scores during antiviral treatment were HCV PCR negative at 24 weeks. This number contrasted significantly with 59\% of patients achieving sustained virological response when the increase of SDS scores was between 10 and 19, and 69\% when less than 10. These results suggested that individuals who experienced a significant increase in depressive symptoms during antiviral treatment may be less likely to achieve sustained virological response.

Other studies described severe psychiatric conditions associated with IFN- $\alpha$ treatment in CHC patients, including suicide attempt or completion [22-23]. One suicide attempt also occurred during the antiviral treatment of our patient and the drug abuse was probably a contributing factor.

Before the 2002 National Institutes of Health (NIH) Consensus Conference on the Management of Hepatitis C [24], psychiatric and/or substance use disorders co-morbidity 
were considered to be partial contraindications to antiviral therapy on CHC patients due to the expected lack of compliance with treatment. An increase in the dropout rate in antiviral treatment for $\mathrm{CHC}$ patients reporting recent illicit drug use have been shown by Knott et al. [25] that found a significant association between drug use in the last 12 months and treatment interruption. Other studies, however, failed to show this association. Dollarhide and colleagues [26] studied retrospectively $130 \mathrm{CHC}$ North-American veterans including subjects with substance abuse and/or dependence. There was no association between treatment completion rates and any specific psychiatric diagnosis, including substance dependence disorders. Robaeys and colleagues [27] studied retrospectively 406 patients, including 98 (24\%) intravenous drug users. No difference in compliance or sustained virological response for $\mathrm{CHC}$ treatment was found between active and non-active intravenous drug users. Schaefer and colleagues [28] studied prospectively 70 CHC patients. Seventeen had no psychiatric disorder or drug addiction (control group), 22 had one psychiatric disorder, 18 had received methadone substitution treatment and 13 were former drug users. All of them were treated with pegylated IFN- $\alpha$ plus ribavirin and assessed using the Montgomery-Asberg Depression Rating Scale and the Brief Psychiatric Rating Scale. These patients presented similar rates of sustained virological response. Moreover, compliance with treatment and the incidence of depressive and psychotic symptoms during antiviral treatment did not differ among groups. These authors concluded that, in an interdisciplinary treatment setting, psychiatric diseases and/ or drug addiction may not affect adherence to treatment and antiviral response rate to treatment [28].

In order to investigate depression in $\mathrm{CHC}$ patients during IFN- $\alpha$ treatment a series of scales and inventories can be used, such as the Hamilton Depression Scale (HAM-D), Montgomery \& Asberg Depression Rating Scale (MADRS), Zung Depression Inventory - Self-Rating Depression Scale (SDS), Hospital Anxiety and Depression Scale (HADS) or Beck Depression Inventory (BDI). These instruments can help the infectious specialist in establishing depression diagnosis based on a systematic approach of psychiatric symptoms and, therefore, to guide therapeutic intervention. It is worth mentioning that different cutoff values can be considered. In order to have higher sensibility for depression diagnosis, a lower cut-off may be warranted. For instance, in a study using HADS, the cutoff value for clinically relevant depression was set at 9 [20]. For the BDI, the scores vary from 0 to 63 points, and scores lower than 10 can be regarded as asymptomatic. Scores of 18 or greater were used to send patients receiving IFN- $\alpha$ to a psychiatric evaluation in order to start antidepressant treatment [29].

The first literature report of the treatment of depression induced by IFN- $\alpha$ in a CHC was in 1994. Nortriptyline was used and the patient evolved with improvement of depressive symptoms [30]. Nortriptyline is considered the less serotoninergic of the tricyclic antidepressants. This is an interesting issue as it has been proposed that one of the most relevant mechanisms in the pathophysiology of depression in this setting is serotoninergic dysfunction [11]. In this sense, the selective serotonin reuptake inhibitors are the most studied antidepressants in patients with depression induced by IFN- $\alpha$ in CHC patients. Among them, citalopram has a good pharmacokinetic and safety profile, with several studies being conducted in such population, including a recent randomized, double-blind, placebo-controlled study with good results [20].

Clomipramine is a tertiary amine considered effective even in severe depression, displaying a dual action in serotonin and norepinephrine pathways. Both clomipramine [31] and bupropion $[32,33]$ have the ability to decrease seizure threshold with higher doses being more epileptogenic. There are also reports of IFN- $\alpha$ and even crack/cocaine to have similar adverse reactions and potential risks [34]. Fortunately, our patient did not develop seizures during treatment. We should also point out that the dopaminergic and noradrenergic effects of bupropion may have similar psychostimulating properties and pathways in the central nervous system to those of crack/ cocaine's [35]. It could also explain the improvement of the patient's craving during treatment.

The final outcome of the patient who suffered a violent death also merits a comment. In Brazil, several studies have shown high mortality rates among crack cocaine users. For instance, Laranjeira and colleagues [36] studied for two years 131 crack cocaine users in São Paulo. In this study, 13 patients died, two disappeared and no information was available on 28. Most deaths were determined by AIDS or homicide. Ribeiro and colleagues [37] reported the extension of this study for a 3 year period. More 23 deaths occurred, and 13 (56.6\%) were attributed to homicide, mainly with a firearm. The overall mortality rate among crack users was more than seven-fold that seen among the general population in São Paulo for the same period [37]. Similar scenarios have been described in other Brazilian large cities [38,39]. At present, homicide is responsible for more than one third of all deaths due to external causes, constituting a major health problem.

In conclusion, the present case highlights the possibility of completing $\mathrm{CHC}$ treatment in patients with psychiatric disorders and/or drug dependence. After the end of antiviral treatment, a closer and extended follow-up of this population by a multidisciplinary health team should be warranted in order to reduce the risk of illicit drug recurrence and other complications.

\section{References}

1. World Health Organization. Hepatitis C - global prevalence (update). Wkly Epidemiol Rec 2000;75:17-28.

2. Di Bisceglie A.M. Hepatitis C and hepatocellular carcinoma. Hepatology 1997;26(3, suppl 1):34S-8S.

3. Kim W.R. The Burden of Hepatitis $\mathrm{C}$ in the United States. Hepatology 2002;36(5, suppl 1):30-4S.

4. Fried M.W., Shiffman M.L., Reddy K.R. et al. Peginterferon alfa2a plus ribavirin for chronic hepatitis $\mathrm{C}$ vírus infection. $\mathrm{N}$ Engl J Med 2002;347:975-82. 
5. Manns M.P., McHutchison J.G., Gordon S.C. et al. Peginterferon alfa-2b plus ribavirin compared with interferon alfa-2b plus ribavirin for initial treatment of chronic hepatitis C: a randomised trial. Lancet 2001;358:958-65.

6. Campos L.N., Guimarães M.D.C., Carmo R.A. et al. HIV, syphilis, and hepatitis B and C prevalence among patients with mental illness: a review of the literature. Cad. Saúde Pública 2008;24(Sup 4):S607-S620.

7. Guimarães M.D.C., Campos L.N., Melo A.P.S. et al. Prevalence of HIV, syphilis, hepatitis B and C among adults with chronic mental illness: a national multicenter study in Brazil. Rev Bras Psiquiatr 2009;31(1):43-7.

8. Almeida R.C., Pedroso E.R.P. Vulnerabilidade e exposição a marcadores sorológicos dos vírus da imunodeficiência humana, hepatites B e C, vírus linfotrópico de células T humanas e sífilis em pacientes psiquiátricos internados em hospital público. Rev Assoc Méd Minas Gerais 2004;14:244-50.

9. Chang T.T., Lin H., Yen Y.S., Wu H.L. Hepatitis B and hepatitis C among institutionalized psychiatric patients in Taiwan. J Med Virol 1993;40:170-3.

10. Focaccia R., da Conceição O.J., Sette H.Jr. et al. Estimated Prevalence of Viral Hepatitis in the General Population of the Municipality of São Paulo, Measured by a Serologic Survey of Stratified, Randomized and Residence-Based Population. Braz J Infect Dis 1998:2(6):269-84.

11. Dieperink E., Willenbring M., HO S.B. Neuropsychiatric Symptoms Associated with Hepatitis C and Interferon Alpha: A Review. Am J Psychiatry 2000;157:867-76.

12. Lotrich F.E., Rabinovitz M., Gironda P. et al. Depression following pegylated interferon-alpha: Characteristics and vulnerability. Journal of Psychosomatics Research 2007;63:131-5.

13. Singh N., Gayowski T., Wagener M.M. et al. Vulnerability to psychologic distress and depression in patients with end-stage liver disease due to hepatitis C virus. Clin Transplant 1997;11(5 Pt 1):406-11.

14. Lee D.H., Jamal H., Regenstein F.G. et al. Morbidity of chronic hepatitis C as seen in a tertiary care medical center. Dig Dis Sci 1997;42(1):186-91.

15. Osher F.C., Goldberg R.W., McNary S.W. et al. Substance abuse and the Transmission of Hepatitis C Among Persons With Severe Mental Ilness. Psychiatric Services 2003;54(6):842-7.

16. American Psychiatric Association: Diagnostic and Statistical Manual of Mental Disorders, Fourth Edition, Text Revision. Washington, DC, American Psychiatric Association, 2000.

17. Raison C.L., Broadwell S.D., Borisov A.S. et al. Depressive symptoms and viral clearance in patients receiving interferonalpha and ribavirin for hepatitis C. Brain Behav Immun 2005;19(1):23-7.

18. Horikawa N., Yamazaki T., Izumi N. et al. Incidence and clinical course of major depression in patients with chronic hepatitis type $\mathrm{C}$ undergoing interferon-alpha therapy: a prospective study. General Hospital Psychiatry 2003;25(1): 34-38.

19. Raison C.L., Borisov A.S., Majer M. et al. Activation of Central Nervous System Inflammatory Pathways by Interferon-Alpha: Relationship to Monoamines and Depression. Biol Psychiatry 2008;Sep 16 [Epub ahead of print].

20. Kraus M.R., Schäfer A., Schöttker K. et al. Therapy of interferoninduced depression in chronic hepatitis $\mathrm{C}$ with citalopram: a randomised, double-blind, placebo-controlled study. Gut 2008;57:531-36.
21. Capuron L., Raison C.L., Musselman D.L. et al. Association of Exaggerated HPA Axis Response to the Initial Injection of Interferon-Alpha With Development of Depression During Interferon-Alpha Therapy. Am J Psychiatry 2003;160:1342-5.

22. Rifflet H., Vuillemin E., Oberti F. et al. Pulsions suicidaires chez des malades atteints d'hépatite chronique $\mathrm{C}$ au cours ou au décours du traitement par l'interféron alpha. Gastroenterol Clin Biol 1998;22:353-57.

23. Janssen H.L.A., Brouwer J.T., Van der Mast R.C., Schalm S.W. Suicide associated with alfa-interferon therapy for chronic viral hepatitis. J Hepatol 1994;21:241-3.

24. National Institutes of Health Consensus Development Conference Panel Statement: management of hepatitis C. Hepatology 2002;36(5, suppl 1):3S-20S.

25. Knott A., Dieperink E., Willenbring M.L. et al. Integrated psychiatric/medical care in a chronic hepatitis C clinic: effect on antiviral treatment evaluation and outcomes. Am J Gastroenterol 2006 Oct;101(10):2254-62.

26. Dollarhide A.W., Loh C., Leckband S.G. et al. Psychiatric comorbidity does not predict interferon treatment completion rates in hepatitis C seropositive veterans. J Clin Gastroenterol 2007;41(3):322-28.

27. Robaeys G., Van Vlierberghe H., Matheï C. et al. Similar compliance and effect of treatment in chronic hepatitis $\mathrm{C}$ resulting from intravenous drug use in comparison with other infection causes. Eur J Gatroenterol Hepatol 2006;18(2):159-66.

28. Schaefer M., Hinzpeter A., Mohmand A. et al. Hepatitis C Treatment in "Difficult-to-Treat" Psychiatric Patients with Pegylated Interferon-Alpha and Ribavirin: Response and Psychiatric Side Effects. Hepatol 2007:46(4):991-98.

29. Hauser P., Khosla J., Aurora H. et al. A prospective study of the incidence and open-label treatment of interferon-induced major depressive disorder in patients with hepatitis C. Molecular Psychiatry 2002;7:942-7.

30. Goldman S.L. Successful Treatment of Interferon Alfa-Induced Mood Disorder With Nortriptyline. Psychosomatics 1994:35(4):412-13.

31. Pisani F., Oteri G., Costa C. et al. Effects of psychotropic drugs on seizure threshold. Drug Saf 2002:25(2):91-110.

32. Dunner D.L., Zisook S., Billow A.A. et al. A prospective safety surveillance study for bupropion sustained-release in the treatment of depression. J Clin Psychiatry 1998:59(7):366-73.

33. Alper K., Schwartz K.A., Kolts R.L. et al. Seizure incidence in psychopharmacological clinical trials: an analysis of Food and Drug Administration (FDA) summary basis of approval reports. Biol Psychiatry 2007;62(4):345-54.

34. Dhuna A., Pascual-Leone A., Langendorf F. Seizure incidence in psychopharmacological clinical trials: an analysis of Food and Drug Administration (FDA) summary basis of approval reports. Epilepsia 1991;32(6):890-94.

35. Papakostas G.I., Nutt D.J., Hallett L.A. et al. Resolution of Sleepiness and Fatigue in Major Depressive Disorder: A Comparison of Bupropion and the Selective Serotonin Reuptake Inhibitors. Biological Psychiatry 2006;60(12): 1350-55.

36. Laranjeira R., Rassi R., Dunn J. et al. Crack cocaine - a two year follow-up of treated patients. J Addict Dis 2001;20(1):43-48.

37. Ribeiro M., Dunn J., Sesso R. et al. Causes of death among crack cocaine users. Rev Bras Psiquiatr 2006;28(3):196-202.

38. Beato-Filho C.C., Assuncao R.M., Silva B.F. et al. Conglomerados de homicídios e o tráfico de drogas em Belo Horizonte, Minas Gerais, de 1995 a 1999. Cad Saúde Pública 2001;17(5):1163-71.

39. Santos S.M., Barcellos C., Carvalho M.S., Flores R. Detecção de aglomerados espaciais de óbitos por causas violentas em Porto Alegre, Rio Grande do Sul, Brasil, 1996. Cad Saude Publica 2001;17(5):1141-51. 